\title{
Análise de Risco aplicada aos alimentos no Brasil: perspectivas e desafios
}

\author{
Risk Analysis applied to food safety in Brazil: \\ prospects and challenges
}

Ana Virgínia de Almei da Figueiredo ${ }^{1}$

Maria Spínola M iranda ${ }^{2}$

${ }^{1}$ Diretoria de Vigilância Sanitária da Secretaria de Saúde do Distrito Federal. SGAN 601, Lotes O/P, Asa Norte. 70830-010 Brasília DF. anavirginia.figueiredo@ gmail.com

${ }^{2}$ Departamento deAnálises Bromatológicas da FaculdadedeFarmácia, UniversidadeFederal da Bahia.
Abstract The scope of this case study is to discuss the ideas of the Brazilian Codex Alimentarius Committee (CCAB) coordinated by $\mathrm{N}$ ational Institute of M etrology, Standardization and Industrial Quality (Inmetro), with respect to the Codex Alimentarius norm on Risk Analysis (RA) applied to Food Safety. The objectives of this investigation were to identify and analyze the opinion of $C C A B$ members on RA and to register their proposals for the application of this norm in Brazil, highlighting the local limitations and potential detected. CCAB members were found to be in favor of the Codex Alimentarius initiative of instituting an RA norm to promotethehealth safety of foods that circulate on the international market. There was a consensus that the Brazilian government should incorporate RA as official policy to improve the country's system of food control and leverage Brazilian food exports. They acknowledge that Brazil has the technical-scientific capacity to apply this norm, though they stressed several political and institutional limitations. The members consider RA to be a valid initiative for tackling risks in food, due to its ability to improve food safety control measures adopted by the government.

Key words Food safety risk analysis, Sanitary surveillance, Food safety
Resumo Trata-sedeum estudo decaso no qual se discutiram asideias do Comitêdo Codex Alimentarius do Brasil (CCAB), coordenado pelo Instituto Nacional de M etrologia, N ormalização e Qualidade Industrial (Inmetro) sobre a norma Codex Alimentarius deA nálise de Risco aplicada aos alimentos (AR). Os objetivos deste trabalho foram identificar e analisar a opinião dos membros do CCAB sobre AR e levantar as propostas para a adoção desta norma no país, destacando as limitações e as potencialidades locais apontadas. Osmembros do CCAB mostraram-sefavoráveis à iniciativa do Codex em instituir a norma AR para promover a segurança sanitária dos alimentos que transitam no mercado internacional. H ouve concordância no sentido de que o governo brasileiro deva incorporar a AR como política oficial para melhorar o sistema de controle de alimentos do país e para fortalecer as exportações brasilei ras de alimentos. Reconheceram que o Brasil dispõe de capacidade técnico-científica para aplicar essa norma, porém destacaram várias limitações político-institucionais. Osmembros reconhecem a AR como uma iniciativa valiosa para enfrentar os riscos dos alimentos, devido a sua capacidade de aprimorar as ações de controle sanitário de alimentos realizadas pel o governo.

Palavras-chave Análise de risco de alimentos, Vigilância sanitária de alimentos, Segurança sanitária dos alimentos 
Introdução

Nas últimas décadas, a preocupação dos consumidores com os riscos relacionados aos alimentos importados e comercializados no mercado local tem-se intensificado, sobretudo devido à ocorrência de surtos originários de fonte comum e da sua rápida disseminação entre os países ${ }^{1-3}$. Tal fato tem pressionado os governos a admitirem a relevância das questões relativas à segurança sanitária de al imentos e a mobilizarem-se em prol da adoção de medidas regulatórias que estabeleçam requisitos sanitários para a comercialização de produtos alimentícios destinados ao consumo humano, para proteger a saúde da população.

Concomitantemente a isso, observam-se, no cenário mundial, a ascensão e o fortalecimento de movimentos sociais que defendem, entre outras bandeiras políticas, os direitos dos consumidores e a preservação do meio ambiente com vistas a enfrentar as contradições econômicas e sociais inerentes ao intenso processo de integração da economia mundial ${ }^{4}$. Soma-se, também, a contestação contra a abertura dos mercados, em especial ao dos alimentos, alegando a falta tanto de transparência no lidar com as questões da saúde quanto de legitimidade dos acordos internacionais do comércio firmados no âmbito da Organização Mundial do Comércio (OMC), os quais sobrepõem os interesses econômicos, em detrimento dos da segurança sanitária ${ }^{5}$.

Aliado ao intenso comércio global dealimentos, as viagens internacionais e a circulação intensa de turistas e viajantes a negócios passam a atuar, também, como fatores de risco para o aumento da exposição das pessoas aos agentes patogênicos nativos - de outras partes do mundo - e aos perigos emergentes. Esses fenômenos, decorrentes do crescente intercâmbio entre bens materiais e povos de diferentes culturas, acentuam-se com a incorporação de novos hábitos alimentares; demudanças nas preferências dosconsumidores; e de práticas de processamento de alimentos que, em seu conjunto, definem a nova conformação epidemiológica das doenças deorigem alimentar no mundo 2,3,6-8.

Em geral, os riscos globais correspondem aos efeitos contraditórios dessa nova convivência além-fronteiras, própria do processo de globalização. Por um lado, ela internacionaliza o sistema de produção e comercialização de produtos e de serviços e aumenta a interdependência econômica, política e social entre os Estados, com a perda da autonomia plena9; por outro, dissemi- na as doenças e potencializa os riscos à saúde da população ${ }^{10,11}$.

Como produto comercial, os alimentos se apresentam de maneira conflituosa no cenário econômico internacional, pois ao mesmo tempo que se constituem a principal mercadoria do comércio entre os países, tornam-se o veículo mais importante de transmissão de doenças infecciosas, comprometendo o comércio e afetando miIhares de pessoas ${ }^{12}$. Reconhecido como um problema amplo de saúde pública, a segurança sanitária dos alimentos passa a representar um de safio transnacional que requer intensa cooperação internacional no estabelecimento de meios efetivos de proteção à saúde das populações, incluindo o fortalecimento dos sistemas de vigilâncias ${ }^{6,12}$, uma vez que as soluções extrapolam a esfera de jurisdição do Estado-nação.

Nas últimas quatro décadas, essa tarefa de disciplinar o comércio internacional, em matéria de identidade e qualidade sanitária dos alimentos, tem sido delegada à Comissão do Codex Alimentarius, criada em 1961 pelo Fundo das $\mathrm{Na}$ ções Unidas para a Alimentação e a Agricultura (FAO) e pela Organização Mundial da Saúde (OMS) para atuar no fortalecimento do comércio internacional de produtos alimentícios, aliando-o aos propósitos de proteger a saúde dos consumidores e de assegurar práticas leais no comércio de alimentos ${ }^{13}$.

A década de 90 constitui um marco para o Codex, pois ele foi reconhecido como referência internacional pela OMC, tornando-se elementochave para dirimir as controvérsias de ordem sanitária, atinentes ao comércio mundial dealimentos $^{14}$. Com isso, inicia-se o processo de desenvolvimento de um método capaz de lidar com os riscos à saúde pública veiculados por alimentos ${ }^{15}$.

O Brasil, país atuanteno comércio internacional de alimentos ${ }^{16}$ e membro oficial da Comissão do Codex, interessado em manter as conquistas comerciais obtidas, proteger os interesses nacionais e viabilizar o seu mercado em expansão, necessita atentar para as regras sanitárias internacionais, avaliando a conveniência de incorporá-las ao seu arcabouço legal e de inserilas no cotidiano das práticas institucionais. Esses elementos, que se associam à preservação da saúde dos consumidores, podem sensibilizar o governo nacional a aderir a essa norma.

Internamente, as discussões sobre os projetos de normas sanitárias internacionais que visam disciplinar o comércio de alimentos são realizadas no âmbito do Comitê Codex Alimentarius do Brasil (CCAB), que, nos últimos anos, 
foi incumbido da tarefa deapreciar os documentos sobre Análise de Risco aplicada aos alimentos (AR). Tal condição torna o CCAB uma instância fértil de conhecimentos e de informações sobre o tema, fazendo suscitar as seguintes indagações a serem investigadas neste estudo: qual a opinião dos membros desse comitê sobre a norma AR adotada pelo Codex Alimentarius (FAO/ OMS)? Quais as recomendações que os membros propõem ao governo brasileiro para viabilizar a aplicação prática da norma AR?

Para tanto, foram definidos os seguintes objetivos: identificar e analisar a opinião dos membros do CCAB sobre a norma AR do Codex Alimentarius e levantar as propostas para a adoção dessa norma no país, incluindo as limitações eas potencialidades locais apontadas.

\section{A Análise de Risco do Codex Alimentarius}

Para conter os custos financeiros investidos pelas empresas e pelo Estado em razão das mudanças na complexidade dos riscos decorrentes das grandes transformações tecnológicas e científicas vivenciadas pela sociedade, surge, na década de 80 , o método científico deAnálise de Risco, cuja aplicação inicial dirigiu-se à segurança industrial, ao meio ambiente e à saúde ${ }^{17}$. Fundamenta-se em uma abordagem científica com caráter multidisciplinar e integrador para identificar, quantificar as relações entre os agentes de riscos e os danose respaldar as alternativas, para mitigar ou aceitar os riscos, as quais serão analisadas e decididas coletivamentepelos diversos atores envolvidos ${ }^{17,18}$.

$\mathrm{Na}$ perspectiva do controleinternacional dos riscos dos alimentos, em 2005 foi aprovada a primeira norma AR intitulada Princípios de aplicación práctica para el análisis de riesgos aplicables en el marco del Codex Alimentarius ${ }^{19}$. Embora o projeto de norma sobre a aplicação da AR dirigida aos governos encontre-se em tramitação ${ }^{20}, 0$ conteúdo essencial dessa norma recentemente aprovada foi a ele incorporado.

A norma Codex de AR aprovada rege-se pelos princípios de efetividade, participação, transparência e atualização à luz dos novos dados científicos e consiste em um método estruturado quecompreende três elementos distintos, porém estreitamente vinculados ${ }^{19}$ :

- Avaliação de risco: fundamenta-se em conhecimentos científicos sobre os perigos e riscos em toda a extensão da cadeia produtiva, os mé todos de controle, a incidência de efeitos prejudiciaisà saúde, tanto agudos quanto crônicos, acu- mulativos e ou combinados, e os grupos da população vulneráveis ou expostos a alto risco;

- Gerenciamento de risco: trata-se do processo de decisão sobreas opções de gerenciamento, o qual deve contemplar as incertezas, as consequências econômicas, a viabilidade técnica, política e econômica, entre outros fatores;

- Comunicação de risco: consiste na difusão das informações às partes interessadas, de forma transparente, a fim de garantir a sua adequada participação eo gerenciamento eficaz dos riscos ${ }^{19}$.

\section{M etodologia}

Trata-se de um estudo de caso único, do tipo exploratório, baseado no trabalho de $\mathrm{Yin}^{21}$, no qual foi selecionado um tema da atualidade para ser investigado com os membros do CCAB. A experiência acumulada de análise crítica dos documentos do Codex determinou a eleição desse colegiado como o foco do estudo em tela.

\section{Caracterização do caso}

O CCAB foi criado em 1980, sob a coordenação do Instituto N acional deM etrologia, N ormalização eQualidadeIndustrial (Inmetro), com o objetivo de analisar e adequar os estudos e os projetos de normas Codex aos interesses nacionai $s^{22}$. Esse comitê congrega representações de oito instituições do governo, cinco entidades do setor produtivo e deuma associação de proteção e de defesa dos consumidores. Seus membros são formalmente indicados por essas 14 representações: Inmetro; M inistérios das Relações Exteriores; da Saúde; da Agricultura, Pecuária e A bastecimento; da Fazenda; da Ciência e Tecnologia; da Justiça; e do Desenvolvimento, Indústria e Comércio Exterior; Associação Brasileira de Indústria de Alimentos; Associação Brasileira de Normas Técnicas; Confederação Nacional da Indústria; Confederação Nacional da Agricultura; Confederação $\mathrm{N}$ acional do Comércio; elnstituto de Defesa do Consumidor ${ }^{22-24}$.

Coleta, processamento e análise dos dados

Para responder Às perguntas e alcançar os objetivos propostos neste estudo, foram utilizadas duas fontes de dados: os documentos e as narrativas das entrevistas com oito membros formais do CCAB.

Quanto à documentação, foram analisadas 33 atas dereuniões do CCAB, no período de 2000 
a 2006, que continham como pauta a AR para verificar a evolução das discussões. Em complementação, foram analisadas as sete Posições Brasileiras referentes ao mesmo período, que correspondem aos documentos oficiais onde constam as considerações, as críticas e as sugestões sobre os projetos de normas a serem defendidas pelo Brasil na ocasião da Reunião do Comitê do Codex AlimentariussobrePrincípios Gerais (CCGP), responsável pela condução da temática de AR.

Optou-se pela técnica da entrevista semiestruturada, porque possibilita extrair os significados que os indivíduos atribuem ao objeto investigado e compreender a lógica que respalda a sua aplicação prática. Após a realização do pré teste, as entrevistas foram previamente agendadas e posteriormente programadas, com cada membro, de forma independente.

Antes de iniciar as entrevistas, os sujeitos da pesquisa foram informados sobre o objetivo da investigação, a gravação das entrevistas, o sigilo das informações e 0 anonimato dos entrevistados. Em seguida, foi apresentado o Formulário deAprovação do Comitê de Ética em Pesquisa do Instituto deSaúdeColetiva da UniversidadeFede- ral da Bahia para conhecimento e, na sequência, entregueo Termo deConsentimento LivreeEsclarecido para ciência, preenchimento eassinatura.

A gravação das entrevistas realizou-se no período de agosto a dezembro de 2006, em Brasília (DF). A pós a leitura das narrativas das entrevistas, adotou-se o Plano de Análise com base nas orientações de Bardin ${ }^{25}$. Os trechos recortados foram analisados à luz das referências teóricas relacionadas à globalização da economia, riscos dos al imentos e segurança sanitária de alimentos (Quadro 1).

\section{Resultadosediscussão}

A impressão geral dos membros do CCAB sobre a instituição da norma de AR do Codex é que tal iniciativa visa promover a segurança sanitária dos alimentos quetransitam no mercado internacional; estimular o comércio justo entre os países; e fundamentar cientificamente as medidas sanitárias impostas pelos países para proteger a saúde dos consumidores, atendendo ao disposto no Acordo de Medidas Sanitárias e Fitossanitárias

Quadro 1. Plano de análise.

\begin{tabular}{|c|c|c|c|}
\hline Unidade & D efini ção & Categoria & Perguntas \\
\hline $\begin{array}{l}\text { Motivação do Codex } \\
\text { para AR. }\end{array}$ & $\begin{array}{l}\text { Relação dos motivos que } \\
\text { impulsionaram o Codex a } \\
\text { desenvolver a norma. }\end{array}$ & $\begin{array}{l}\text { Interesses para o } \\
\text { desenvolvimento da } \\
\text { AR. }\end{array}$ & \multirow{2}{*}{$\begin{array}{l}\text { Qual a sua opinião } \\
\text { sobre a iniciativa do } \\
\text { Codex Alimentarius em } \\
\text { propor a AR para lidar } \\
\text { com os alimentos? }\end{array}$} \\
\hline $\begin{array}{l}\text { Valoração da atitude do } \\
\text { Codex em aprovar a AR. }\end{array}$ & $\begin{array}{l}\text { Especificação das vantagens } \\
\text { da norma. }\end{array}$ & $\begin{array}{l}\text { Impactoseconômicos } \\
\text { e sociais. }\end{array}$ & \\
\hline $\begin{array}{l}\text { Adoção da norma } \\
\text { de AR pelo governo. }\end{array}$ & $\begin{array}{l}\text { Exposição dos argumentos } \\
\text { que embasam a conduta } \\
\text { sugerida para o governo. }\end{array}$ & $\begin{array}{l}\text { Ordem do governo } \\
\text { para promover e } \\
\text { respaldar a AR. }\end{array}$ & $\begin{array}{l}\text { O que o governo deve } \\
\text { fazer para implementar } \\
\text { a AR? } \\
\text { O que deve fazer para } \\
\text { viabilizar a avaliação de } \\
\text { risco? }\end{array}$ \\
\hline $\begin{array}{l}\text { Operacionalização da } \\
\text { norma de AR pelo } \\
\text { governo. }\end{array}$ & $\begin{array}{l}\text { Especificação dos pontos } \\
\text { divergentes da norma. } \\
\text { Explicação dos passos e } \\
\text { estratégias a serem seguidas } \\
\text { pelo governo para adotar a } \\
\text { AR. } \\
\text { Listagem dos aspectos } \\
\text { promissores e dos obstáculos } \\
\text { para a adoção da AR. }\end{array}$ & $\begin{array}{l}\text { Condutas para } \\
\text { concretizar AR, } \\
\text { aproveitando as } \\
\text { potencialidades } \\
\text { disponíveise } \\
\text { suplantando as } \\
\text { dificuldades. }\end{array}$ & $\begin{array}{l}\text { Quais as propostas de } \\
\text { diretrizes para a } \\
\text { implementação da AR? } \\
\text { Quais as facilidades e as } \\
\text { dificuldades no } \\
\text { processo de } \\
\text { implementação da AR? }\end{array}$ \\
\hline Atores sociais da AR. & $\begin{array}{l}\text { I dentificação dos atores sociais } \\
\text { eas razões para o envolvimento } \\
\text { deles com AR. }\end{array}$ & $\begin{array}{l}\text { Participação dos } \\
\text { atores sociais no } \\
\text { processo de AR. }\end{array}$ & $\begin{array}{l}\text { Quem deve participar } \\
\text { do processo de AR? }\end{array}$ \\
\hline
\end{tabular}


(SPS) da OMC. Os três aspectos destacados se complementam entre si e denotam a validade dessa norma internacional.

Além disso, os membros acrescentaram que a AR promoverá o aperfeiçoamento do processo de elaboração de normas Codex, evitando que sejam estabelecidas regras motivadas principalmente pelas pressões econômicas e políticas.

É provável que essas pressões não sejam atenuadas, uma vez que o desejo deintrodução crescente de novas tecnologias na produção de alimentos - sem a investigação científica exaustiva que avalie e delimite os riscos sobre a saúde humana e ambiental - é corrente no mundo atual. A lógica imperante é a de regulamentar, mas não contrariar o ritmo das tecnologias que aumentam a produtividade e, consequentemente, a lucratividade dos negócios comerciais ${ }^{26}$.

Os membros reconhecem que, em um processo de globalização, as regras internacionais terminam por influenciar a condução das políticas internas, impondo ajustes que merecem ser incorporados pelo país para que este se mantenha no patamar de competitividade almejado no comércio internacional de alimentos.

Esse fato demonstra a perda gradual da soberania e da autonomia dos Estados-nação devido à globalização, como registram vários autores ${ }^{4,10,26,27}$, e a el evação da competitividade nos mercados como objetivo máximo das políticas estatais. Os Estados-nação passam, então, a sofrer as interferências das decisões tomadas no âmbito das organizações internacionais e perdem o controle pleno sobre os negócios do próprio Estado.

Os participantes do CCAB admitem que a conjunção de interesses comerciais e de proteção à saúde dos consumidores motivou a Comissão do Codex a desenvolver a norma internacional sobre $A R$, e reconhecem que a ligação do Codex aos interesses do comércio tenha sobressaído devido ao seu vínculo com a OMC. Apontam como fatos a ocorrência de intensos debates vinculados ao comércio que sobreleva o tema "mercado" em comparação com as questões de saúde e a atuação marcante de lobistas no Codex.

Ao aprofundar a análise, os membros afirmam que a relevância do caráter comercial da norma Codex está na inter-relação do Codex com a OM C. Explicam, ainda, quea busca de alternativas para enfrentar as contradições do mercado de alimentos e ordená-lo segundo a ótica das regras sanitárias foi o elemento central para a aprovação dessa norma. A expansão das relações econômicas, a intensificação dos riscos e surtos epi- dêmicos supranacionais, a pressão dos consumidores e as demandas comerciais impulsionaram a OM C a reconhecer as normas Codex como referência internacional, pelo seu fundamento científico, e a criar a demanda por AR.

0 ritmo das transformações econômicas mundiais dos anos 90, que permitiu o maior intercâmbio comercial dealimentos entre os países centrais e os periféricos, gerou um descompasso na capacidade de aprimoramento da segurança sanitária dos produtos em circulação oriundos dos países periféricos. Desse modo, os membros acreditam que um dos efeitos positivos da AR sobre o comércio leal de alimentos será a harmonização dos procedimentos entre os países centrais e periféricos, levando à equi valência entre os produtos similares em circulação no mercado internacional quanto ao grau de segurança sanitária, uma vez que está se adotando o mesmo método para controlar os riscos.

Nessa perspectiva, a AR é identificada, por esse grupo, como uma proposta proveniente dos países desenvolvidos - os importadores de alimentos. Todavia, é certo que o esboço da AR já constava da proposta formulada pela comunidade europeia, representada por um grupo de países que atua de forma articulada e que, portanto, exerce influência marcante nas decisões adotadas pela Comissão do Codex.

N osúltimos anos, as reestruturações no campo da segurança dos alimentos ocorridas nos países europeus estão alinhadas com o Libro blanco sobre seguridad alimentaria ${ }^{28}$. 0 documento reúne as diretrizes da nova política alimentar da União Europeia voltada à elevação dos níveis de segurança sanitária dos produtos alimentícios e define a AR como a base dessa política, conduzindo ao planejamento global eintegrado da cadeia produtiva de alimentos e à organização coordenada e integrada das ações.

Em face do exposto, é possível que essa publicação tenha servido de inspiração para a elaboração da norma Codex, pois, como lembra Lucchesi ${ }^{26}$, as normas e as recomendações derivadas desses organismos internacionais, em geral, refletem o conhecimento científico conjugado aos interesses econômicos e políticos dos países desenvolvidos.

Depreende-se, também, que o poder hegemônico exercido por esse grupo de países extrapola as relações econômicas e inclui a capacidade de impor seus model os científicos para a realização do controle sanitário oficial nos países periféricos. A esses últimos, que se destacam como exportadores de alimentos, resta a obrigação de 
controlar os efeitos negativos das tecnologias utilizadas na produção de alimentos, segundo os moldes especificados pelos países importadores - os compradores.

Por essa ótica é que os membros ligados ao segmento produtivo identificam a AR como parte integrante da política comercial dirigida aos exportadores de alimentos, pois são el es que necessitam adequar os seus produtos aos padrões internacionais para se manterem estáveis no mercado externo.

Observa-se a clareza que os membros têm sobrea utilidade daAR para o comércio exterior, e pouco édestacada a sua importância na preservação da qualidade sanitária dos produtos de circulação interna e na proteção da saúde da comunidade local.

Análise de Risco do Codex: discutindo a sua prática

Os membros do CCAB reconhecem a importância da AR para o Brasil e concordam que o governo deveria incorporá-la como política oficial para lidar com os riscos relativos aos alimentos. Os argumentos apresentados em sua defesa se fundamentam no reconhecimento da coerência desse instrumental, dos êxitos para a mel horia do sistema de controle de alimentos de qualquer país e das vantagens auferidas ao país ao focalizar o comércio internacional.

Entendem que os efeitos positivosda AR para o mercado externo, em que o agronegócio é o motor da economia, estão nos incrementos das exportações dealimentos ena ampliação do mercado internacional, pois a adoção de padrões internacionais que representam o consenso mundial qualifica a segurança sanitária dos produtos alimentícios nacionais e dificulta a existência de barreiras comerciais.

Preocupados com a imprevisibilidade dos resultados desse trabalho sobre as exportações de alimentos devido às condições político-econômicas e ao aparato técnico-operacional disponível que possibilitem fornecer uma resposta satisfatória, os membros entendem que é necessário ter cautela quanto à $A R$.

A aplicação da AR implica enfrentar os riscos presentes na totalidade da cadeia produtiva de alimentos, em vez de tratar isoladamente os riscos inerentes a cada segmento em particular. Isto remete, diretamente, à complexa estrutura organizacional do país envolvida no controle sanitário dos alimentos - constituída por várias instituições com comandos distintos para lidar com os riscos -, a qual foi alvo de reflexões e críticas pelos membros do CCAB. Entre os comentários mencionados, destacam-se a falta de integração entre os órgãos, a duplicidade de ação e o modelo incompatível com as necessidades atuais, aspectos que demonstram a insatisfação com a estrutura vigente.

Para viabilizar a AR, o grupo entende ser necessária a identificação de estratégias para administrar o conjunto diversificado de instituições envolvidas e apontou três estratégias distintas para lidar com essa realidade institucional:

(1) AR sob um comando político-institucional único. Propõem a reorganização do Estado brasileiro, ou seja, a formação de uma nova estrutura institucional única, coordenada pelo setor público de saúde, mediantea retirada deáre as de competências de dentro das estruturas da agricultura e saúde responsáveis pelo controle sanitário de alimentos, subordinando-a à Presidência da República. Desta forma, acreditam que as duplicidades e os conflitos de ação possam ser superados.

(2) AR como responsabilidade da Presidência da República. Os membros reconhecem que esse trabalho extrapola o âmbito das instituições que hoje realizam o controle sanitário de alimentose, portanto, é um tema de interesse nacional que deveser conduzido pela Presidência da República.

(3) AR sob a coordenação de uma instância supraministerial ou interministerial. Osmembros sugerem quese organizeuma instância colegiada com representação ministerial, selecionada em razão da competência relacionada com a commodity de exportação ou com o segmento da cadeia produtiva em questão. A proposta circunscreve-se às demandas relativas aos produtos de exportação.

Astrês alternativas suscitam a necessidade de se repensar a atual estrutura dicotomizada de controle sanitário de alimentos do Brasil, quanto à capacidade de promover agilidade e efetividade das ações prestadas, racionalização das atividades regulatórias e uso eficiente dos recursos públicos. Observa-se que essas posições apontam trajetórias distintas: a instituição de uma política de Estado, criando uma nova instância político-administrativa responsável por gerenciar os riscos, centralizando e concentrando as atividades de controle sanitário de alimentos; ou a formulação de uma política de $A R$, que mantenha a diversidade institucional e aposte na efetividade da estratégia de articulação.

A pesar da criação da Agência $\mathrm{Nacional}$ de Vigilância Sanitária (Anvisa), na década de 90, con- 
cebida segundo o prisma do modelo gerencial, com espaço definido de participação da sociedade, mantém-se a responsabilidade parcial sobre 0 controle sanitário da cadeia produtiva de alimentos. A sinalização dos membros do CCAB para quea AR seja assumida pela Presidência da República sugere a incapacidade político-institucional da Anvisa e das demais instâncias de controle de alimentos para comandar o processo de AR.

Adianta-se que um possível rearranjo institucional não contraria os princípios do Sistema Único de Saúde; ao contrário, para modificar a lógica de pensar e de atuar em segurança de alimentos, é necessário atentar para as regras dispostas nesse sistema, tais como comando único, integração, participação e descentralização das ações.

A emergência e a complexidade dos riscos sanitários ea urgência na adoção de medidas para gerenciar os riscos, em um cenário institucional de poderes fragmentados e sem coordenação única, têm mobilizado vários países a promover uma reorganização administrativa e atualização institucional, com vistas a reduzir os entraves burocráticos que impedem a atuação eficaz e rápida do Estado, como ocorreu, por exemplo, na França ${ }^{29}$ e na Espanha ${ }^{30}$.

Outros países, como Dinamarca, Alemanha, Reino Unido, Países Baixos, Irlanda, Nova Ze lândia e Canadá, também optaram pela consolidação dos seus sistemas oficiais de segurança sanitária de alimentos em uma única agência governamental, para atender ao interesse público; aperfeiçoar a segurança sanitária dos alimentos; e melhorar a eficiência e a efetividade dos programas de controle nacionais ${ }^{31}$.

Esses países suplantaram vários desafios, inclusive o deneutralizar as resistências coorporativas, e já alcançaram resultados positivos como a redução da superposição deações, a definição clara das responsabilidades e a maior consistência e agilidade no processo de regulamentação $0^{29-31}$.

Outro ponto de reflexão levantado pelos membros do CCAB reside no tratamento discriminatório dado aos alimentos pelas instituições públicas, concentrando os esforços e adotando critérios rígidos de controle sanitário para os produtos destinados ao mercado externo, enquanto para os alimentos de consumo doméstico há flexibilidade nos critérios estabelecidos e investimentos limitados.

Essa diferença de conduta institucional entre os alimentos conforme o seu destino deve-se à valorização das atividades agroindustriais ${ }^{32} \mathrm{e}$, provavelmente, aos impulsos corporativos refe- ridos por Bodstein ${ }^{33}$. Conforme a autora, tratase do poder que certas corporações exercem sobre o Estado, expressando as suas demandas nos espaços decisórios governamentais e fazendo com que essas sejam contempladas nas políticas públicas, no caso os produtores e os exportadores de alimentos.

Por fim, aderir à AR significa enfrentar o desafio de desenvolver políticas e condutas institucionais articuladas, integrais e dinâmicas, com capacidade de intervir sobre os riscos à saúde da população derivados dos alimentos com rapidez e com flexibilidade, considerando os impactos gerados. I mplica, também, atuar de forma transparente, valorizar o conhecimento científico e garantir a participação de todos os interessados para que se obtenha uma resposta efetiva elegítima do Estado.

Análise de Risco do Codex:

desvendando seus componentes

A condição atribuídaàs normas Codex, como referência internacional, possibilita aos paísesmembros optarem pela adesão parcial ou integral ao conteúdo dessas normas. Entretanto, os membros entendem que a internalização dessa norma, pelo governo brasileiro, deve contemplar os aspectos de interesse para o país, mediante a prévia avaliação da capacidade tecnológica e político-institucional disponível para fornecer uma resposta satisfatória e evitar entraves nas relações comerciais da nação.

Nesse sentido, os membros fizeram ressalvas a determinados aspectos constantes da norma do Codex sobre AR.

\section{Avaliação de Risco}

0 primeiro ponto refere-se à separação funcional preconizada entre a avaliação e o gerenciamento de risco. No entendimento dos membros, a avaliação de risco não deve ser um trabaIho de domínio exclusivo dos cientistas eser concebida totalmente independente das questões políticas eoperacionais, pois acarreta um distanciamento da realidade por parte dos especialistas. Isso repercutirá sobre as respostas dadas às demandas que terminam por, nem sempre, se rem factíveis de implantação em face dos impactos econômicos, sociais e políticos gerados.

0 risco não se compreende a algo eminentementetécnico-científico, pois se apresenta revestido designificado sociopolítico ecultural ${ }^{34}$. Retirar o caráter de neutralidade científica do risco possibilita aos atores sociais envolvidos contes- 
tar o objeto estudado, gerando divergências e antagonismos quanto à forma de intervenção, que polariza os benefícios sociais e a expansão das atividades econômicas.

Assim, os membros sugeriram que a coordenação das atividades de avaliação de risco ficasse sob a responsabilidade de um técnico do governo, o qual assumiria o papel de manter 0 grupo de avaliadores inseridos no contexto da realidadesocial.

A pesar de reconhecerem que cabeà instância governamental a incumbência do gerenciamento de risco, não constatam inconveniências em haver participação governamental como avaliador de risco, quando forem identificados técnicos do governo que atendem aos critérios de qualificação estabelecidos e que dominam o objeto a ser avaliado.

A intenção da norma Codex é proporcionar maior independência ao processo de avaliação derisco; todavia, flexibilizá-la não implica necessariamente prejuízos na sua aplicação. As críticas formuladas apresentam como ponto comum a ampliação da presença do governo na avaliação de risco, e os argumentos apresentados buscam valorizar as potencialidades profissionais existentes na esfera do governo e direcionar os trabaIhos da avaliação de risco à luz da realidade concreta em busca de resultados efetivos.

O segundo ponto relaciona-se ao princípio de precaução constante na $A R$, quando os membros reconhecem que há indícios do uso indevido de medidas precautórias como forma de restrição do comércio internacional dealimentos, 0 que coincide com o relato feito por vários autores $9,26,35,36 ;$ ou quando há omissão do governo em utilizar esse postulado em situações que se justificam.

Ancorada em pressupostos de que a verdade científica é relativa e provisória ${ }^{37}$ e de que o conhecimento produzido segundo as condições da modernidade apresenta apenas uma estabilidade relativa ${ }^{27}$, a norma AR considera as incertezas e a variabilidade da informação científica no processo de Análise de Risco eadmite, portanto, o princípio da precaução. Nessas circunstâncias, esse postulado jurídico torna-se polêmico e suscita reflexões com focos divergentes: como elemento deestagnação do desenvolvimento científico, por impor a suspensão da atividade produtiva ou comercial; ou como sinalizador da necessidade de maior investimento em ciência e tecnologia para tornar o risco cientificamente conhecido $0^{5}$.

No entanto, não se pode descartar totalmente a razão da desconfiança, pois tais restrições são consideradas um dos tipos mais frequentese importantes debarreiras não alfandegárias ${ }^{26}$. Este fato se comprova quando, no ano de 2006, os países fizeram 585 notificações à OM C, sendo que $31 \%$ delas foram motivadas por questões relativas à segurança sanitária de alimentos ${ }^{36}$. Porém, o ideal é associar a aplicação do postulado com investimentos na ampliação dos requisitos de segurança sanitária dos produtos e no aperfeiçoamento dos mecanismos de defesa e de proteção à saúde dos consumidores.

Outro tema polêmico, expresso pelos membros do CCAB, reside na inserção dos fatores ambientaisnaAR. Eles entendem quetal preocupação extrapola a missão do Codex e é objeto de discussão no âmbito do fórum que administra o Protocolo de Cartagena ${ }^{38}$.

Merece atentar que, no mundo moderno, a globalização dos riscos se manifesta em termos de intensidade e de expansão ${ }^{27}$, por ameaçar a toda a humanidade ou afetar um grande contingente de pessoas. Desse modo, já não se pode tratar isoladamente os riscos, inclusive os provenientes dos alimentos, dissociados do meio ambiente, pois os eventos globais estão em plena interconexão ${ }^{39}$. Essa situação impõe ao CCAB ampliar os horizontes de entendimento dos riscos atuais dos alimentos e das tecnologias a eles aplicadas, os quais não se restringem a causar ameaças à vida humana, mas também ao meio ambiente, tanto pela perda da biodiversidade quanto pela contaminação ambiental, buscando romper as barreiras que os impedem de reconhecer as contradições do "progresso" técnico-econômico.

Gerenciamento de risco

0 gerenciamento de risco, como tarefa a ser assumida pelo governo, significa lidar primeiramentecom escolhas e decisões sociopolíticaseculturais e, em seguida, com o estabelecimento das atividades técnicas e legais necessárias para intervir nos riscos ${ }^{34}$. A proposta degerenciamento participativo do Codex busca a extensão da democracia e a incorporação da ciência ao processo decisório para tornar mais efetiva a capacidade de intervenção do governo e facilitar a mediação dos conflitos, importando disputas de interesses. Agir dessa maneira significa ampliar as chances de solucionar os problemas, de modo eficaz, em prol da saúde da coletividade ${ }^{40-42}$. Embora o governo seja o coordenador do processo degerenciamento, para os membros todos os atores envolvidos devem participar dessa atividade.

Ao tratar do gerenciamento de risco em uma perspectiva internacional, os membros atestam 
que a discussão dos projetos de normas internacionais em um fórum com representação tripartite como o CCAB é suficiente para alcançar o consenso em torno de uma posição que reflita 0 interesse de todos os participantes.

Quanto à participação da sociedade civil na $A R$, constata-se que o assunto se comportou como o divisor de águas do posicionamento dos participantes do Comitê. Para um deles, a participação da sociedade civil está devidamente visualizada no gerenciamento derisco, eaponta a consulta pública e a audiência pública como ferramentas úteis para os órgãos gestores envolverem a sociedade civil. Além disso, menciona, como importante, a realização de um fórum representativo específico - consumidores, indústrias, universidades - para se discutir e divulgar os resultados da avaliação de risco, antes de uma tomada de decisão.

Outro posicionamento associa a representação da sociedadecivil especificamenteno momento da comunicação de risco, descartando a sua presença nasatividades científicas egerenciais dos riscos.

Por fim, defende-sea ideia da participação da sociedade civil, ou mesmo do cidadão, no processo integral deAR para garantir que os resultados decorrentes valorizem os interesses do consumidor em vez dos do mercado.

Observa-se que a norma do Codex ${ }^{20}$ supera politicamentealguns posicionamentos dosmembros e amplia o espaço de participação da sociedade civil, referida como representação dos consumidores, pois contempla a sua participação no processo de definição da política de avaliação de risco e nas atividades de gerenciamento e comunicação de risco.

A interferência de novos atores sociais nas políticas de vigilância sanitária é algo recente e surge com o advento do processo democrático dos anos 80, influenciado pelo movimento da Reforma Sanitária. A pesar disto, as políticas continuam a manter o traço característico, no decorrer das gestões governamentais, da presença marcante do Estado e do setor produtivo como formuladores dessa política e do atendimento restrito às demandas que expressam os interesses coletivos ${ }^{43}$.

A presença organizada equalificada dosconsumidores nas atividades de AR constitui um re forço para a defesa dos interesses coletivos e os habilita a exercer o controle social efetivo, tanto contribuindo e conferindo legitimidade às ações propostas quanto reivindicando a revisão dos atos decisórios adotados; e sempre que for iden- tificada uma relação injusta entre os benefícios para a sociedade e as medidas de intervenção pública estabelecidas para limitar o impacto dos riscos sobre a saúde do coletivo. Em um ambiente democrático, a tomada de decisões envolve arranjos complexos, devido aos diversos interesses em jogo, ea decisão é, em parte, resultante do conhecimento científico, conjugada a interesses políticos e econômicos.

Bodstein ${ }^{33}$ sinaliza que 0 avanço da sociedade democrática moderna está na geração de novos direitos sociais e na ampliação do espaço público com a inserção dos novos atores. $O$ estabelecimento de parceria entreo Estado ea sociedade civil eo uso da ciência para a mediação dos conflitos são estratégias para o alcance de ações efetivas contra os riscos globalizados.

Os membros destacaram que a heterogeneidade no perfil educacional da sociedade brasileira, quenão possibilita a todos exercer plenamente a sua cidadania e influenciar nos negócios do Estado para que prevaleça o interesse coletivo, impõe a necessidade de haver uma interlocução competente e comprometida com a causa pública. D essa forma, alertam que a atuação si stemática do M inistério Público e das entidades civis, como representantes de parte da população brasileira, em especial dos grupos socialmente excluídos, torna-se imprescindível para a defesa de seus interesses.

Aspectos operacionais da Análise de Risco

De acordo com os membros do CCAB, para operacionalizar a AR, no Brasil, cabe efetuar uma articulação com os especialistas e as instituições afins para envolvê-los no processo, considerando a capacidade técnico-científica disponível no país, nas esferas pública e privada.

O conhecimento das experiências de avaliação de risco aplicada na área de agropecuária, concentradas nas culturas de exportação, eo das experiências desenvolvidas em outros países foram apontados como alguns dos caminhos para se iniciarem as atividades.

Para esse Comitê, o grupo deespecialistasresponsável pela avaliação de risco deveter conhecimento técnico-científico eindependência; refletir a representação de várias instituições; eser oficialmente formalizado. O CCAB defende a transparência do processo de avaliação derisco, para que a sociedade conheça os critérios que levaram à conclusão dos trabalhos dos avaliadores de risco.

Para solucionar os possíveis conflitos e as pressões de interesses diversos a que seriam sub- 
metidos os especialistas, os membros mencionaram que 0 ideal seria 0 aporte técnico-financeiro do Estado para a formação de uma "massa pensante". Segundo Guimarães ${ }^{44}$, há pessoal qualificado e capacidade instalada de pesquisa, na saúde, no âmbito das instituições públicas. Porém, o M inistério da Saúde necessita reafirmarse como liderança política na condução dos assuntos relativosà política de ciência, tecnologiae inovação em saúde e redefinir os padrões de pesquisa em saúde no país, considerando as prioridades da política social no setor.

A ampliação do financiamento governamental das pesquisas científicas, associada à verificação da integridade e da indepen dência dos agentes envolvidos na produção do conhecimento científico, pode priorizar estudos envolvendo os impactos das tecnologias à saúde humana e ambiental que somente interessam às instituições públicas, assim como evitar situações que induzam ao descrédito do conhecimento quando os resultados afetarem os interesses econômicos ${ }^{45}$.

Como a ciência édecisiva no processo deavaliação, é conveniente que haja o confronto entre os diferentes resultados da produção científica e das experiências acadêmicas para a consolidação da avaliação. Ressalta-se que o conhecimento científico que sustenta a avaliação de risco é reconhecidamente instável, permeado por significado sociopolítico e cultural ${ }^{34}$, relativo e provisó$\mathrm{rio}^{37}$, e se reestrutura continuamente na ótica da reflexividade da sua aplicação prática ${ }^{27}$. Essa dinâmica do saber é que impõe uma atualização frequente da avaliação de risco anteas novas descobertas científicas.

Embora os membrosadmitam ser uma questão de difícil controle, a observância dos princípios éticos pelos especialistas responsáveis pela avaliação de risco é fundamental para que os resultados produzidos não se desviem em prol da valorização dos interesses privados. As inquietações dos membros envolvem desconfiança, preocupação e mecanismo de controle do comportamento ético do especialista, próprios da sociedade moderna, em que há desencontros entre a lógica do capital e a da ética. Para Dallari ${ }^{46}$, a globalização da economia éincompatível com os preceitos éticos ao reger-se pelas leis mercadológicas, uma vez que o poder econômico influencia decisões e utiliza meios diversos para converter em proveito econômico os resultados científicos e os avanços tecnológicos no campo da saúde.

Considerando a publicação recente dessa nor$m a^{19}$ e a absorção lenta do tema pelas universidadesedemais instituições públicas e privadas, dife- rentes estratégias de sensibilização e de divulgação da norma foram apontadas como parte integrante dessa política: a realização deseminários, a formulação de programas de capacitação e a instituição de uma comissão. A aplicação da AR pressupõe o envolvimento de diferentes atores sociais. São eles, assumindo diferentes papéis, quevão explicar os riscose as incertezas e definir - deforma participativa - como fazer a interven ção. Por isso, torna-se necessário criar situações que possibilitem sensibilizar esses atores para que possam não só compreender, mas também participar, ativamente, do processo de AR.

Segundo os membros, a inexistência de liderança nacional na área de segurança de alimentos amplia os obstáculos para a AR. É preciso apresentar-se, no cenário político, um ator capaz de instigar o debate no âmbito da sociedade, em defesa de propostas atualizadas, que modernize os conceitos e as práticas de controle de al imentos e sensibilize a população sobre a importância de intervir nos riscos transnacionais associados aos alimentos.

\section{Conclusão}

Os membros do CCAB reconhecem a AR como uma iniciativa valiosa da Comissão do Codex Alimentarius para enfrentar os riscos associados aos alimentos que circulam no comércio internacional. Os novos espaços sociais de interlocução e de participação, envolvendo o governo, a sociedade e o setor produtivo e os mecanismos de transparência das ações adotadas, previstos na norma AR, possibilitam a tomada de valiosaa para debatendem que a de AR.envolvimento da AR erdecisão efetivamente compartida para a contenção dos riscos da modernidade, que ameaçam a saúde do coletivo.

O CCAB é favorável que o governo brasileiro incorpore a norma AR na sua prática institucional, com o fim de aprimorar o sistema nacional de controle de al imentos e ampliar a proteção da saúde dos consumidores e, consequentemente, fortalecer as exportações brasileiras dealimentos.

Não obstante a capacidade técnico-científica para desencadear o processo de AR, a presença de vários poderes institucionais, a fragmentação das ações e a condução de políticas distintas pe las instituições envolvidas com o controle sanitário de alimentos constituem-se em dificuldades, cuja superação está na condução da AR pela Presidência da República ou em novos rearranjos institucionais em direção a um comando ins- 
titucional único. Estaúltima alternativa pode facilitar o processo decisório da AR e o desencadeamento de medidas plenas, sistemáticas e preventivas dos riscos dos alimentos, que afetam as comunidades interna e externa, considerando o perfil agroexportador brasileiro.

\section{Colaboradores}

AVA Figueiredo trabalhou na coleta, na análise dos dados e na redação final do artigo; MS M iranda atuou como orientadora e revisora.

\section{Agradecimentos}

Ao apoio dos membros do Comitê do Codex Alimentarius do Brasil, o qual foi fundamental para o desenvolvimento deste estudo.

\section{Referências}

1. Herwaldt BL, Ackers M, The Cyclospora Working Group. An outbreak in 1996 of Cyclosporiasis associated with imported raspberries. N Engl J M ed 1997; 336(22):1548-1556.

2. Tauxe RV. Emerging foodborne diseases: an evolving public health challenge. Emerg Infect Dis 1997; $3(4): 425-434$.

3. Katz D, Kumar S, Malecki J, Lowdermilk M, Koumans EHA, Hopkins R. Cyclosporiasis associated with imported raspberries, Florida, 1996. California Public Health Rep 1999; 114:427-438.

4. Santos T. Economia mundial: integração \& desenvolvimento sustentável. Petrópolis: Vozes; 1993.

5. Dallari SG, Ventura DFL. O princípio da precaução: dever do Estado ou protecionismo disfarçado? Perspectivas 2002; 16(2):53-63.

6. Altekruse SF, Swerdlow DL. The changing epidemiology of foodborne diseases. Am J Med Sci 1996; 311(1):23-29.

7. Taormina PJ, Beuchat LR, Slutsker L. Infections associated with eating seed sprouts: an international concern. Emerg Infect Dis 1999; 5(5):626-634.

8. Evans MR, Sarvotham T, Thomas DR, H oward AJ. Domestic and travel-related foodborne gastrointestinal illness in a population health survey. Epidemiol Infect 2006; 134:686-693.

9. Ventura DFL. Direito Internacional Sanitário. In: Brasil. Ministério da Saúde. Direito sanitário e Saúde Pública. Brasília: M inistério da Saúde; 2003. p. 261-299. (Série E. Legislação de Saúde).

10. Beck U. O que é globalização? Equívocos do globalismo: respostas à globalização. São Paulo: Paz e Terra; 1999.

11. Fisher IS, Threlfall EJ. The enter-net and Salmgene databases of foodborne bacterial pathogens that cause human infections in Europe and beyond: an international collaboration in surveillance and the development of intervention strategies. Epidemiol Infect 2005; 133:1-7.

12. Käferstein FK, M otarjemi Y, Bettcher DW. Foodborne disease control: a transnational challenge. Emerg Infect Dis 1997; 3(4):503-510.

13. Food and Agriculture Organization of the U nited Nations, World Health Organization. (FAO/WHO). Understanding the Codex Alimentarius. Revised and updated. Rome: FAO/WHO; 2005.
14. Food and Agriculture Organization of the United Nations, World Health Organization. (FAO/WHO). Food safety and globalization of trade in food: a challenge to the public health sector. Rev 1. Rome: FAO/ WHO; 1998.

15. Food and Agriculture Organization of the United Nations, World Health Organization. (FAO/WHO). Joint FAO/WHO Expert Consultation. Application of risk analysis to food standard issues $1995 \mathrm{M}$ ar 1317, Geneve, Switzerland. Rome: FAO/WH O; 1995.

16. World Trade Organization (WTO). International trade statistics. Statistics database. Time series: network of world merchandise trade. [cited 2006 Dec 12]. Available from: http://stat.wto.org/StatisticalProgram/ WSDBViewD ata. aspx? Language $=\mathrm{E}$

17. Freitas CM, Gomez CM. Análise de riscos tecnológicos na perspectiva das ciências sociais. Hist, Cienc. Saúde - M anguinhos 1996/1997; 3(3):485-504.

18. Porto M F, Freitas CM. Análise de riscos tecnológicos ambientais: perspectivas para o campo da saúde do trabalhador. Cad Saude Publica 1997; 13(Supl.2): 59-72.

19. Organización de las Naciones Unidas para la Agricultura y la Alimentación, Organización Mundial de la Salud (FAO/OMS). Comisión del Codex Alimentarius: manual de procedimiento. 14ạ ed. Roma: FAO/OM S; 2005. (Programa Conjunto FAO/OM S sobre N ormas Alimentarias).

20. Food and Agriculture Organization of the United Nations, World Health Organization. (FAO/WHO). Joint FAO/WHO Food Standards Programme Codex Committee on General Principles. Proposed draft working principles for risk analysis for food safety. $24^{\text {th }}$ session, Paris, France; 2007 April 2-6.

21. Yin RK. Estudo de caso: planejamento e métodos. Porto Alegre: Bookman; 2005.

22. Conselho Nacional de M etrologia, N ormalização e Qualidade Industrial (Conmetro). Resolução no 01/ 80, de 17 de março de 1980, do Conselho Nacional de M etrologia, Normalização e Qualidade Industrial (Conmetro). Cria no âmbito do Inmetro o Comitê de Coordenação do Codex Alimentarius e institui os membros. [documento na Internet]. [acessado 2006 abr 28]. Disponível em: http://www. inmetro.gov.br/resc/ 
23. Conselho Nacional de M etrologia, N ormalização e Qualidade Industrial (Conmetro). Resolução n 12, de 24 de agosto de 1992, do Conselho Nacional de M etrologia, Normalização e Qualidade Industrial (Conmetro). Altera os itens 2, 3, 4 e 5 da Resolução Conmetro no 01/80. [documento na Internet]. [acessado 2006 abr 28]. Disponível em: http://www. inmetro.gov.br/resc/

24. Conselho Nacional de Metrologia, Normalização e Qualidade Industrial (Conmetro). Resolução no 5, de 26 de maio de 1993, do Conselho Nacional de M etrologia, Normalização e Qualidade Industrial (Conmetro). Altera o item 1 da Resolução Conmetro no 12, de 24 de agosto de 1992. [documento na Internet]. [acessado 2006 abr 28]. Disponível em: http://www.inmetro.gov.br/resc/

25. Bardin L. Análise de conteúdo. Lisboa: Edições 70; 2004.

26. Lucchesi G. A internacionalização da regulamentação sanitária. Cien Saude Colet 2003; 8(2):537-555.

27. Giddens $A$. As conseqüências da modernidade. São Paulo: Ed. Unesp; 1991.

28. Comisión de las Comunidades Europeas (COM). Libro Blanco sobre Seguridad Alimentaria. Bruselas, Bélgica: COM ; 2000. [COM (1999)719 final]. [documento na Internet]. [citado en 2007 fev 9]; [cerca de 62p.]. Disponible en: http//www.ec.europa.eu/dgs/ health_consumer/library/pub/pub06_es.pdf

29. Durand CA. A segurança sanitária num mundo global: aspectos legais - O Sistema de Segurança Sanitária na França. Revista de Direito Sanitário 2001; 2(1):59-78.

30. Agencia Española de Seguridad Alimentaria (AESA). Memoria 2002. Madrid; 2003. [citado en $2007 \mathrm{fev}$ 11]. Disponible en: http://www.aesan.msc.es/aesa/ web/A esaPageServer?idpage $=9$

31. United States Government Accountability Office (GAO). Food safety: experiences of seven countries in consolidating their food safety systems. Report to Congressional Requesters GAO-05-212, Washington, DC. Feb. 2005. [documento na Internet]. [cited 2007 Feb 22]. Available from: http://www.gao.gov/ new.items/d0521.pdf

32. Costa EA. Vigilância Sanitária: proteção e defesa da saúde. São Paulo: Hucitec, Sobravime; 1999.

33. Bodstein RCA. Complexidade da ordem social contemporânea e a redefinição da responsabilidade pública. In: Rozenfeld S, organizador. Fundamentos da Vigilância Sanitária. Rio de Janeiro: Editora Fiocruz; 2000. p. 63-97.

34. Nardocci AC. Gerenciamento social de riscos. Revista de Direito Sanitário 2002; 3(1):64-78.

35. Carvalho LA. Barreiras técnicas e OMC. In: CarvaIho LA, H age JA, organizadores. OM C: estudos introdutórios. São Paulo: IOB Thompson; 2005. p. 149-164.
36. Centro de Estudos Avançados em Economia Aplicada (Cepea/Esalq/USP). Barreiras sanitárias e fitossanitárias ao comércio internacional. Informativo Semanal SPS [periódico na Internet]. $2006 \mathrm{dez}$. [acessado $2007 \mathrm{fev} \mathrm{11];} \mathrm{2(50):[cerca} \mathrm{de} 4$ p.]. Disponível em: http://www.cepea.esalq.usp.br/sps/

37. Laville C, Dione J. O nascimento do saber científico. In: Laville C, Dione J. A construção do saber: manual de metodologia da pesquisa em ciências sociais. Porto Alegre: Editora Artes M édicas Sul ; Belo Horizonte: Editora UFM G; 1999. p. 17-47.

38. Brasil. Ministério da Ciência e Tecnologia. Protocolo de Cartagena sobre Biossegurança. 2003. [acessado 2007 fev 11]. Disponível em: .http://www.mct.gov.br/ index.php/content/view/12940.html

39. Capra F. A teia da vida: uma nova compreensão científica dos sistemas vivos. São Paulo: Cultrix; 1996.

40. Peci A. Novo marco regulatório para o Brasil da pós-privatização: o papel das agências reguladoras em questão. RAP 1999; 33(4):121-135.

41. Farias MEM. Políticas públicas e controle social. Boletim Científico 2003; 7:75-80.

42. Costa EA. Vigilância Sanitária: contribuição para 0 debate no processo de elaboração da Agenda de Prioridades de Pesquisa em Saúde. In: Brasil. Ministério da Saúde. Saúde no Brasil: contribuições para a Agenda de Prioridades de Pesquisa. Brasília: M inistério da Saúde; 2004. p. 127-155.

43. Souto AC. Saúde e política: a Vigilância Sanitária no Brasil 1976-1994. São Paulo: Sociedade Brasileira de Vigilância de M edicamentos; 2004.

44. Guimarães R. Ciência, tecnologia e inovação: um paradoxo na Reforma Sanitária. In: Lima NT, Gerschman S, Edler, FC, Suárez JM , organizadores. Saúde e democracia: história e perspectives do SUS. Rio de Janeiro: Editora Fiocruz; 2005. p. 235-256.

45. Barreto ML. O conhecimento científico e tecnológico como evidência para políticas e atividades regulatórias em saúde. In: 8o Seminário Temático Contribuição da Epidemiologia para a Vigilância Sanitária. Brasília; 2002. Braślia: Anvisa; Salvador: UFBA; 2002. p. 67-78.

46. Dallari DA. Ética sanitária. In: Brasil. M inistério da Saúde, organizador. Direito sanitário e Saúde Pública. Brasília: M inistério da Saúde; 2003. p. 66-86.

Artigo apresentado em 03/12/2007

Aprovado em 14/04/2008

Versão final apresentada em 10/05/2008 